\title{
Identification of key genes induced by platelet-rich plasma in human dermal papilla cells using bioinformatics methods
}

\author{
HAIYAN SHEN ${ }^{*}$, HANXIAO CHENG ${ }^{*}$, HAIHUA CHEN and JUFANG ZHANG \\ Department of Plastic Surgery, Hangzhou First People's Hospital, \\ Nanjing Medical University, Hangzhou, Zhejiang 310006, P.R. China
}

Received October 8, 2015; Accepted October 6, 2016

DOI: $10.3892 / \mathrm{mmr} .2016 .5988$

\begin{abstract}
Dermal papilla cells (DPCs) are located at the base of hair follicles, and are known to induce hair follicle regeneration. Platelet-rich plasma (PRP) functions in hair follicle regeneration. To investigate the influence of PRP on DPCs, the present study analyzed RNA-seq data of human hair dermal papilla cells (HHDPCs) that were treated or untreated by PRP. The data included in the RNA-seq were from two normal and two treated HHDPC samples. Following identification by Cuffdiff software, differentially expressed genes (DEGs) underwent enrichment analyses, and protein-protein interaction networks were constructed using Cytoscape software. Additionally, transcription factor (TF)-DEG and TF-long non-coding RNA (lncRNA) regulatory networks were constructed. A total of 178 differentially expressed lncRNA were screened, 365 were upregulated and 142 were downregulated. Notably, upregulated cyclin dependent kinase 1 (CDK1) (degree=76), polo-like kinase $1(P L K 1)($ degree=65), cell division cycle 20 (degree=50), cyclin B1 (degree=49), aurora kinase B (degree $=47)$, cyclin dependent kinase $2($ degree $=46)$ and downregulated $\mathrm{v}$-myc avian myelocytomatosis viral oncogene homolog $(M Y C)$ (degree=12) had higher degrees in networks. In addition, CCAAT/enhancer binding protein $\beta$, E2F transcription factor $1(E 2 F 1)$, early growth response 1 and $M Y C$ may be key TFs for their target genes, and were enriched in pathways associated with the cell cycle. They may also be involved in cell proliferation via various interactions with other genes, for example CDK1-PLK1 and $E 2 F 1 \rightarrow C D K 1$.
\end{abstract}

Correspondence to: Dr Jufang Zhang, Department of Plastic Surgery, Hangzhou First People's Hospital, Nanjing Medical University, 261 Huansha Road, Hangzhou, Zhejiang 310006, P.R. China

E-mail: jufangzhangjf@163.com

*Contributed equally

Key words: human dermal papilla cells, platelet-rich plasma, differentially expressed genes, protein-protein interaction network, regulatory network
These dysregulated genes induced by PRP may affect proliferation of HHDPCs.

\section{Introduction}

As a type of dermal cell located in the base of the hair follicle, dermal papilla cells (DPCs) have the ability to induce hair follicle regeneration and hair growth (1). Platelet-rich plasma (PRP) is plasma enriched with a higher proportion of platelets, compared with that with that which is usually found in whole blood. $\alpha$-granules in platelets contain growth factors, indicating that PRP has the ability to promote cell proliferation and differentiation (2). Previous studies have reported that PRP may induce mesenchymal stem cell proliferation and chondrogenic differentiation in vitro (3-5). It has been reported that PRP is essential in hair follicle regeneration (6). Thus, it was hypothesized that PRP may contribute to hair follicle regeneration via changes in DPC proliferation levels. Hair follicle regeneration is currently known to have an impact in treating alopecia and dermal wounds $(7,8)$. The initial generation of a hair follicle is intimately linked with signal exchange between mesenchymal and epithelial cells via the formation of hair placodes $(9,10)$. Alopecia is defined as a loss of hair from the body or head, and may be induced by nutritional deficiencies, fungal infection and traumatic damage (11). Increased chronic ulcers, skin disease, trauma caused by burns and accidental skin defects mean the restoration of dermal wounds is becoming an important medical concern (12). Thus, it is important to investigate the influence of PRP on DPC and develop therapeutic strategies for hair follicle regeneration.

Previous studies have investigated mechanisms of hair follicle regeneration. For example, S100 calcium binding protein A4 and S100 calcium binding protein A6 may be important in activating stem cells at the beginning of follicle regeneration $(13,14)$. Wingless-type mouse mammary tumor virus integration site family member $10 \mathrm{~b}$ promotes hair follicle growth and regeneration via activation of the canonical Wnt signaling pathway and, thus, may be used as therapeutic target in the treatment of hair follicle-associated diseases $(15,16)$. Via the Gpr44 receptor, prostaglandin D2 may function in inhibiting hair follicle regeneration (17). As a crucial ATPase of the BAF chromatin-remodeling complex, brahma-related gene 1 may regulate the processes 
of epidermal repair and hair regeneration in bulge stem cells (18).

Preliminary studies demonstrated that PRP at a concentration of 5\% should be used to treat human hair DPCs (HHDPCs) in the present study (data not shown). Using RNA-seq data of HHDPCs from normal samples and samples treated with 5\% PRP, the present study aimed to identify differentially expressed genes (DEGs) and predict their possible function using Gene Ontology (GO) and pathway enrichment analyses. The interactions and associations between the DEGs were investigated using protein-protein interaction (PPI) networks. Furthermore, regulatory networks were constructed to screen key genes and transcription factors (TFs).

\section{Materials and methods}

PRP preparation. Samples of whole blood $(10 \mathrm{ml})$ were taken from the median cubital vein of each of the 8 male, healthy participants (mean age, 24.9 years) and mixed with 3.2\% sodium citrate (vol/vol=10:1). PRP was prepared using a two-step centrifugation method. Firstly, the whole blood was centrifuged at $400 \mathrm{x} g$ for $10 \mathrm{~min}$ at room temperature, allowing separation of blood into three layers, the topmost platelet-poor plasma layer, an intermediate PRP layer and the bottommost red blood cell layer. Subsequently, the upper two layers were centrifuged again at 3,800 $\mathrm{x} g$ for $10 \mathrm{~min}$ at room temperature. The platelets in PRP were activated by $0.2 \mathrm{ml} 10 \% \mathrm{CaCl}_{2}$ and $1,000 \mathrm{U}$ bovine thrombin. After a $10 \mathrm{~min}$ incubation, PRP was centrifuged at $1,500 \times \mathrm{g}$ for $5 \mathrm{~min}$ at room temperature, and the supernatant was stored at $-80^{\circ} \mathrm{C}$. All participants provided informed consent, and the present study was approved by the ethics committee of the Hangzhou First People's Hospital (Hangzhou, China).

HHDPCs cultivation. At $37^{\circ} \mathrm{C}$ in a humidified $5 \% \mathrm{CO}_{2}$ incubator (Thermo Fisher Scientific, Inc., Waltham, MA, USA), the HHDPCs (Shanghai Hu Zheng Industrial Co., Ltd., Shanghai, China) were cultivated in a medium consisting of $10 \%$ fetal bovine serum (FBS; Gibco; Thermo Fisher Scientific, Inc.), RPMI-1640 medium (Gibco; Thermo Fisher Scientific, Inc.) and $1 \%$ double antibody (Gibco; Thermo Fisher Scientific, Inc.). HHDPCs were passaged at $80-90 \%$ confluence and pancreatin was used for digestion (Gibco; Thermo Fisher Scientific, Inc.). Subsequently, the cells were centrifuged at $300 \mathrm{x} g$ for $5 \mathrm{~min}$ at room temperature and the supernatant was removed. HHDPCs were preserved in a frozen stock solution which consisted of $10 \%$ dimethyl sulfoxide, $40 \%$ FBS and $50 \%$ RPMI-1640.

RNA extraction and RNA-seq library construction. Following cell counting, HHDPCs were spread on 6-well plates (Applied Biosystems; Thermo Fisher Scientific, Inc.; $2 \times 10^{5}$ cells/well) and starved for $24 \mathrm{~h}$. HHDPCs in the treatment group were treated with 5\% PRP whilst the HHDPCs in the control group were treated with RPMI-1640 medium containing 10\% FBS and $1 \%$ penicillin-streptomycin solution. Each experiment was repeated twice. Total RNA from HHDPC treatment samples and normal HHDPC samples was extracted using TRIzol (Invitrogen; Thermo Fisher Scientific, Inc.), according to the manufacturer's protocols. The purity and integrity of total RNA were checked by a spectrophotometer (Merinton Instrument, Ltd., Beijing, China) and 2\% agarose gel electrophoresis. Following this, the RNA-seq library was prepared using NEBNext ${ }^{\circledR}$ Ultra $^{\text {TM }}$ RNA Library Prep Kit for Illumina ${ }^{\circledR}$ (New England Biolabs, Inc. Ipswich, MA, USA) according to the manufacturer's protocols. Briefly, mRNAs were isolated and divided into $200 \mathrm{nt}$ fragments. Subsequently, double-stranded cDNAs were synthesized and modified, and DNA cluster amplification was performed using a Phusion ${ }^{\circledR}$ Human Specimen Direct Polymerase Chain Reaction kit (Thermo Fisher Scientific, Inc.). The reaction mixture was subjected to the following cycling conditions: An initial denaturation step at $94^{\circ} \mathrm{C}$ for $30 \mathrm{sec}$, followed by 11 cycles of denaturation at $98^{\circ} \mathrm{C}$ for $10 \mathrm{sec}$, annealing at $65^{\circ} \mathrm{C}$ for $30 \mathrm{sec}$ and extension at $72^{\circ} \mathrm{C}$ for $30 \mathrm{sec}$, and a final extension step at $72^{\circ} \mathrm{C}$ for $5 \mathrm{~min}$. Using Illumina HiSeq 2500 v4 100PE (Illumina, Inc., San Diego, CA, USA), high-throughput sequencing was conducted for the RNA-seq library.

DEGs screening. RNA-seq data were preprocessed by the Next Generation Sequencing Quality Control Toolkit (19). Any sequences containing $>20 \%$ bases with a quality value $<20$ were filtered out. Using TopHat2 software (ccb.jhu. edu/software/tophat/index.shtml) (20), RNA-seq data was aligned to human genome hg19, which was downloaded from the University of California, Santa Cruz website (genome. ucsc.edu) (21). The parameter was set as no-mixed and other parameters used default settings. Cuffdiff software (cufflinks. cbcb.umd.edu/) (22) was used to identify the DEGs between RNA-seq data of normal HHDPCs and treated HHDPCs. The adjusted $\mathrm{P}<0.05$ and $\mid \log _{2}$ fold change $(\mathrm{FC}) \mid>1$ served as the cut-off criteria.

Functional and pathway enrichment analysis. GO analysis aims to describe subcellular location, molecular function and the biological processes of gene products (23). The Kyoto Encyclopedia of Genes and Genomes (KEGG) pathway database introduces functions of molecules or genes (24). Using the GOFunction (25) of bioconductor (www.bioconductor.org/), as well as annotation files GO.db (26) and org.Hs.eg.db (27), GO and KEGG pathway enrichment analyses were performed for the DEGs. $\mathrm{P}<0.05$ and $\geq 2$ genes enriched in one pathway served as the cut-off criteria.

PPI network construction. The STRING online software (28) was applied to screen interactions of proteins encoded by DEGs, and the Cytoscape software (www.cytoscape.org/) (29) was used to visualize the PPI network. A combined score $>0.7$ was used as the cut-off criterion.

Regulatory network construction. Using information provided by the ENCODE website (genome.ucsc.edu/ENCODE/encode. hg17.html) regarding $\mathrm{TF}$ binding sites, (30), in addition to genetic and long non-coding RNAs (lncRNAs) location information on the genome, differentially expressed TF-DEG pairs and differentially expressed TF-differentially expressed lncRNA pairs were screened. A certain amount of overlapping occurred between TF binding sites and the cut-off criterion was defined as 1,000 bp upstream to $500 \mathrm{bp}$ downstream of the transcription start site. 
Table I. Pathways enriched for upregulated genes.

\begin{tabular}{|c|c|c|c|c|c|}
\hline Category & Term & Description & $\begin{array}{c}\text { Gene } \\
\text { number }\end{array}$ & Gene symbol & P-value \\
\hline KEGG & 4110 & Cell cycle & 25 & $B U B 1, B U B 1 B$ & $<0.0001$ \\
\hline KEGG & 4914 & Progesterone-mediated oocyte maturation & 12 & CCNA2, CCNB1 & $8.13 \times 10^{-8}$ \\
\hline KEGG & 4114 & Oocyte meiosis & 13 & $A U R K A, B U B 1$ & $2.12 \times 10^{-7}$ \\
\hline KEGG & 5130 & Pathogenic Escherichia coli infection & 8 & $A C T B, A C T G 1$ & $1.10 \times 10^{-5}$ \\
\hline KEGG & 4115 & p53 signaling pathway & 8 & $C C N B 1, C C N B 2$ & $4.72 \times 10^{-5}$ \\
\hline KEGG & 4145 & Phagosome & 11 & $A C T B, A C T G 1$ & 0.000182 \\
\hline KEGG & 4540 & Gap junction & 8 & $C D K 1, P D G F R B$ & 0.000346 \\
\hline KEGG & 3030 & DNA replication & 5 & FEN1, MCM3 & 0.000614 \\
\hline KEGG & 4974 & Protein digestion and absorption & 7 & COL18A1, COL2A1 & 0.000971 \\
\hline KEGG & 4510 & Focal adhesion & 11 & $A C T B, A C T G 1$ & 0.001748 \\
\hline
\end{tabular}

KEGG, Kyoto Encyclopedia of Genes and Genomes; $B U B 1$, BUB1 mitotic checkpoint serine/threonine kinase; $B U B 1 B$, BUB1 mitotic checkpoint serine/threonine kinase $\mathrm{B} ; C C N A 2$, cyclin A2; CCNB1, cyclin B1; AURKA, aurora kinase A; ACTB, $\beta$-actin; $A C T G 1, \gamma$-actin $1 ; C C N B 2$, cyclin B2; $C D K 1$, cyclin dependent kinase 1; PDGFRB, platelet derived growth factor receptor $\beta$; $F E N 1$, flap structure-specific endonuclease 1; $M C M 3$, mini chromosome maintenance complex component 3; COL18A1, collagen type XVIII $\alpha 1$ chain; COL2A1, collagen type II $\alpha 1$ chain.

Table II. Pathways enriched for downregulated genes.

\begin{tabular}{|c|c|c|c|c|c|}
\hline Category & Term & Description & $\begin{array}{l}\text { Gene } \\
\text { number }\end{array}$ & Gene symbol & P-value \\
\hline KEGG & 4115 & p53 signaling pathway & 6 & $B B C 3, C C N D 2$ & $<0.0001$ \\
\hline KEGG & 250 & $\begin{array}{l}\text { Alanine, aspartate and glutamate } \\
\text { metabolism }\end{array}$ & 3 & ASNS, GLS2, GOT1 & 0.002425 \\
\hline KEGG & 5219 & Bladder cancer & 3 & $C D K N 1 A, M Y C, V E G F A$ & 0.005288 \\
\hline KEGG & 4010 & MAPK signaling pathway & 7 & DDIT3, DUSP2 & 0.00709 \\
\hline KEGG & 330 & Arginine and proline metabolism & 3 & GLS2, GOT1, SAT1 & 0.010639 \\
\hline KEGG & 910 & Nitrogen metabolism & 2 & $A S N S, G L S 2$ & 0.016056 \\
\hline KEGG & 4964 & $\begin{array}{l}\text { Proximal tubule bicarbonate } \\
\text { reclamation }\end{array}$ & 2 & GLS2, PCK2 & 0.016056 \\
\hline KEGG & 4110 & Cell cycle & 4 & $C C N D 2, C D K N 1 A$ & 0.020687 \\
\hline KEGG & 4612 & Antigen processing and presentation & 3 & CIITA, HLA-DQA1, HLA-DQA2 & 0.026471 \\
\hline KEGG & 5310 & Asthma & 2 & $H L A-D Q A 1, H L A-D Q A 2$ & 0.026583 \\
\hline
\end{tabular}

KEGG, Kyoto Encyclopedia of Genes and Genomes; BBC3, BCL2 binding component 3; CCND2, cyclin D2; ASNS, asparagine synthetase (glutamine-hydrolyzing); GLS2, glutaminase 2; GOT1, glutamic-oxaloacetic transaminase 1; CDKN1A, cyclin dependent kinase inhibitor 1A; $M Y C$, v-myc avian myelocytomatosis viral oncogene homolog; VEGFA, vascular endothelial growth factor A; DDIT3, DNA damage inducible transcript 3; DUSP2, dual specificity phosphatase 2; SAT1, spermidine/spermine N1-acetyltransferase 1; $P C K 2$, phosphoenolpyruvate carboxykinase, mitochondrial; CIITA, class II major histocompatibility complex transactivator; HLA-DQA1, major histocompatibility complex, class II, DQ $\alpha$ 1; HLA-DQA2, major histocompatibility complex, class II, DQ $\alpha 2$; MAPK, mitogen-activated protein kinase.

\section{Results}

DEGs analysis. Compared with normal HHDPC samples, there were 365 upregulated and 142 downregulated genes screened in the treated HHDPC samples. Furthermore, 178 differentially expressed (including 131 upregulated and 47 downregulated) IncRNAs were identified in the treated HHDPC samples.

Functional and pathway enrichment analysis. The enriched KEGG pathways for upregulated genes were listed in Table I, including cell cycle $(\mathrm{P}<0.0001)$, progesterone-mediated oocyte maturation $(\mathrm{P}<0.0001)$ and DNA replication $(\mathrm{P}=0.000614)$. The enriched KEGG pathways for downregulated genes included p53 signaling pathway $(\mathrm{P}<0.0001)$, mitogen-activated protein kinase signaling pathway $(\mathrm{P}=0.00709)$ and cell cycle $(\mathrm{P}=0.020687$; Table II $)$. In addition, no GO functions were enriched for the DEGs.

PPI network analysis. The PPI network for upregulated genes had 192 nodes and 1,017 interactions (Fig. 1). In this network, 


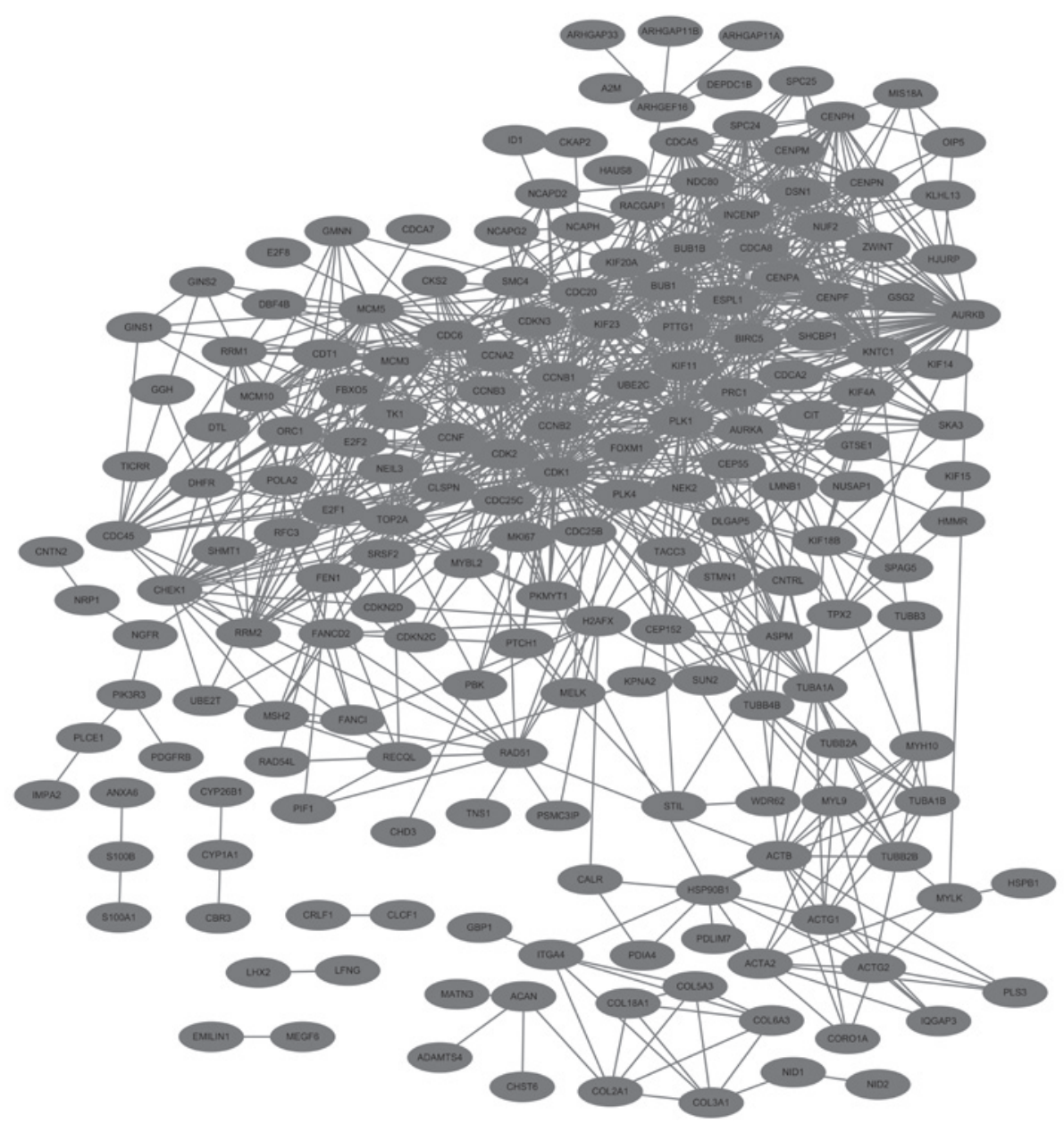

Figure 1. Protein-protein interaction network for upregulated genes. The gray nodes represent the upregulated genes.

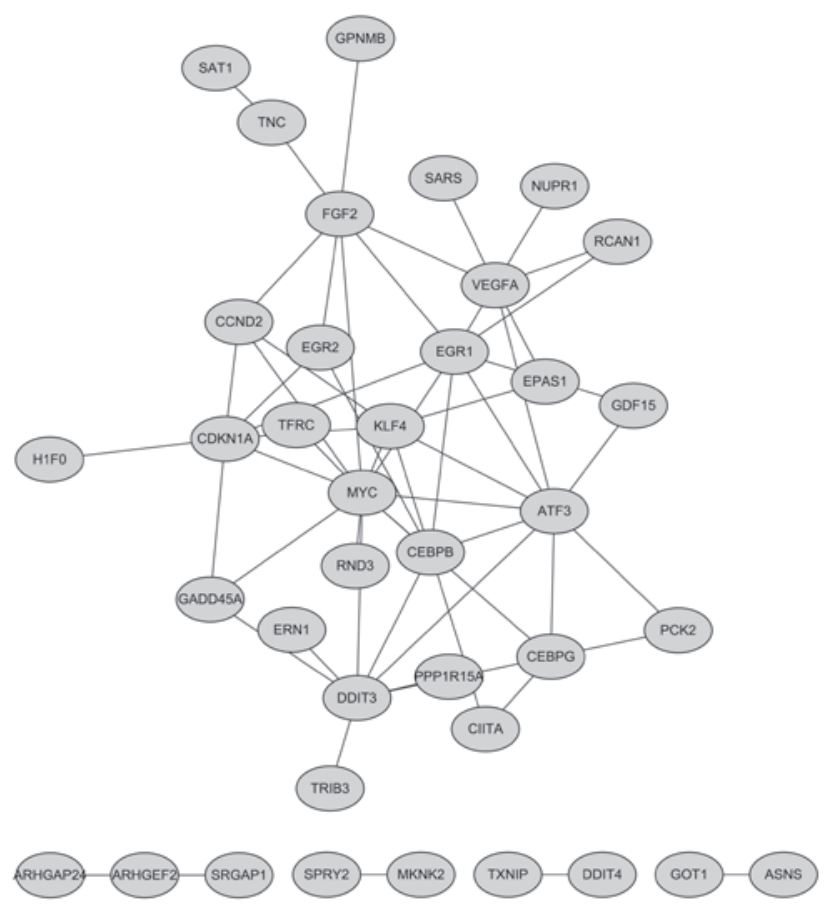

Figure 2. Protein-protein interaction network for downregulated genes. The gray nodes indicate the downregulated genes. cyclin-dependent kinase 1 (CDK1, degree=76), polo-like kinase 1 (PLK1, degree=65), cell division cycle 20 (CDC20, degree $=50)$, cyclin B1 (CCNB1, degree=49), aurora kinase B (AURKB, degree $=47)$ and cyclin-dependent kinase 2 (CDK2, degree $=46$ ) demonstrated higher degrees. In addition, these genes interacted with each other for example, $C D K 1-P L K 1$, $C D C 20-C C N B 1, A U R K B-C D K 2$ and $C D K 1-A U R K B$ in the PPI network.

The PPI network for downregulated genes had 38 nodes and 58 interactions (Fig. 2). In this network, c-myc (MYC, degree $=12$ ), activating transcription factor 3 (degree=9), DNA-damage-inducible transcript 3 (degree $=8$ ) and early growth response 1 (EGRl, degree=8) indicated higher degrees.

Regulatory network analysis. A total of 453 TF-DEG pairs and 530 TF-lncRNA pairs were identified. The TF-DEG and TF-lncRNA regulatory networks are presented in Figs 3 and 4. Notably, the target genes of TFs CCAAT/enhancer binding protein- $\beta(C / E B P-\beta), \mathrm{E} 2 \mathrm{~F}$ transcription factor $(E 2 F) 1, E G R 1$ and $M Y C$ were enriched in pathways associated with the cell cycle. In the TF-DEG regulatory network, these TFs targeted $C D K 1, P L K 1, C C N B 1$ and $A U R K B$ (for example, $M Y C \rightarrow P L K 1$, $M Y C \rightarrow C C N B 1, M Y C \rightarrow A U R K B, C E B P B \rightarrow A U R K B$, $E 2 F 1 \rightarrow C D K 1$ and $E 2 F 1 \rightarrow C C N B 1)$. 


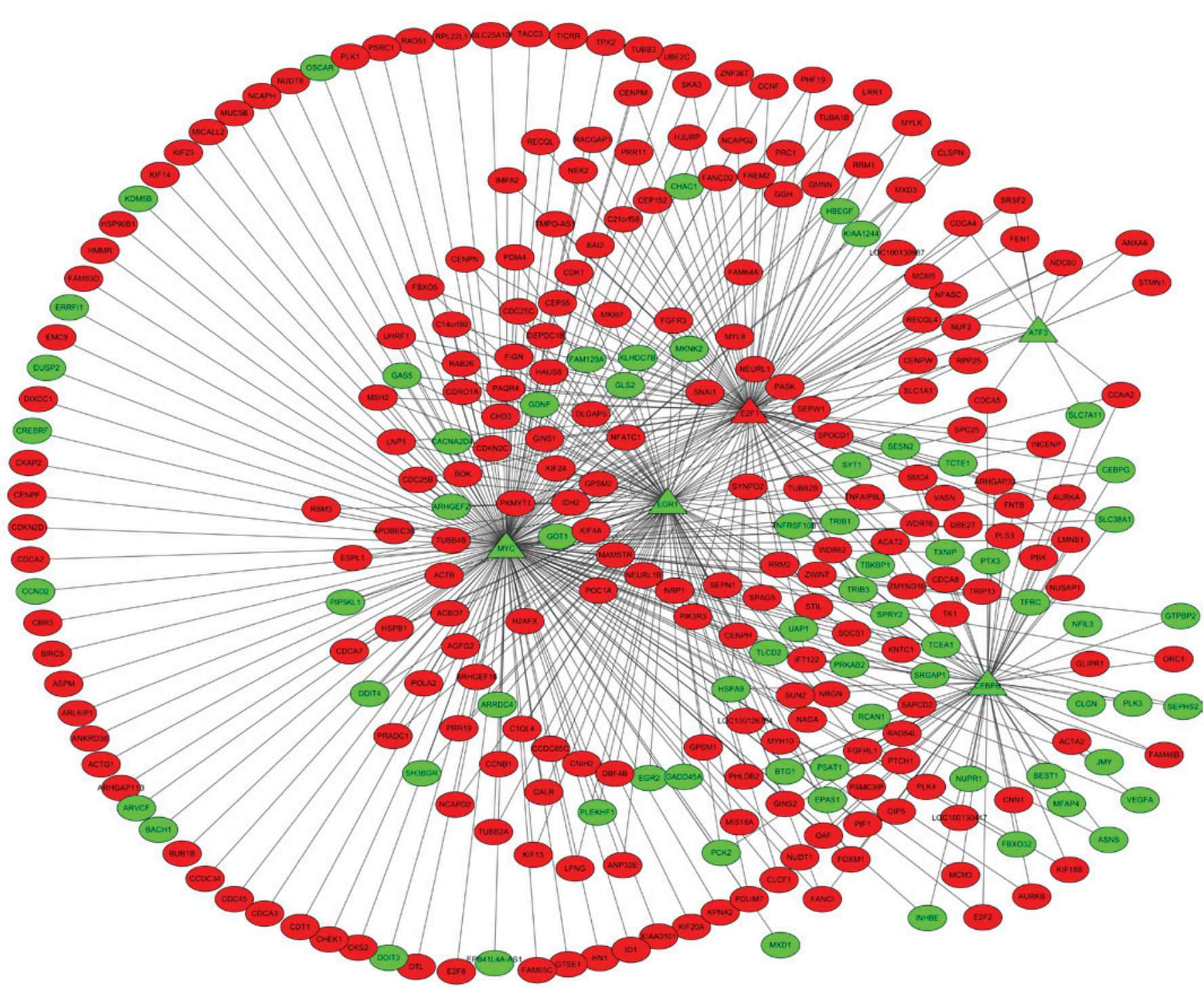

Figure 3. TF-DEG regulatory network. The red and green nodes represent upregulation and downregulation, respectively. The circles and triangles indicate for DEGs and TFs, respectively. TF, transcription factor; DEG, differentially expressed gene.

\section{Discussion}

The present study screened 178 differentially expressed lncRNA, 365 upregulated genes and 142 downregulated genes in treated HHDPC samples compared with normal HHDPC samples. Only selected DEGs and lncRNAs have been presented in the present study. DEGs enriched in pathways have been listed in Tables I and II. Pathway enrichment indicated that these upregulated and downregulated genes were enriched in proliferation-associated pathways, including those involved in the cell cycle and DNA replication, indicating that PRP may affect cell proliferation of HHDPCs. The DEGs and lncRNAs that were key nodes in the networks have been mentioned. In the PPI networks, upregulated $C D K 1$ (degree=76), $P L K 1$ (degree=65), $C D C 20$ (degree $=50), C C N B 1$ (degree $=49), A U R K B($ degree $=47), C D K 2$ (degree=46) and downregulated $M Y C$ (degree=12) had higher degrees. Furthermore, $C E B P B, E 2 F 1, E G R 1$ and $M Y C$, which may be key TFs for their target genes, were enriched in pathways associated with the cell cycle.
$C D K 1$ activity is continuously required to ensure continuing end resection and to maintain a double-strand break-induced checkpoint. Furthermore, $C D K 1$ is involved in later stages of homologous recombination (31). It has been demonstrated that $C D K 1$ is the only crucial cell cycle CDK and is able to drive cell division alone (32). As an important moderator of cell division (33), $P L K 1$ is essential for mitotic entry at the appropriate time (34). PLK1 appears to be required for centrosome-mediated microtubule activities and spindle assembly. In addition, siRNAs targeted against PLK1 may be potential anti-proliferative agents that inhibit neoplastic cells $(35,36)$. This suggests that $C D K 1$ and $P L K 1$ may be associated with cell proliferation.

CDC20 can activate anaphase-promoting complex (APC/C) in metaphase of the cell cycle, and its $\mathrm{C}$ terminus contains a WD40 repeat domain that regulates protein-protein interactions $(37,38)$. Suppression of $C C N B 1$, which is a cyclin controlling mitotic entry, induces a marked arrest of $\mathrm{G}_{2} / \mathrm{M}$ phase in HCT116 and SW480 cells, preventing the expression 


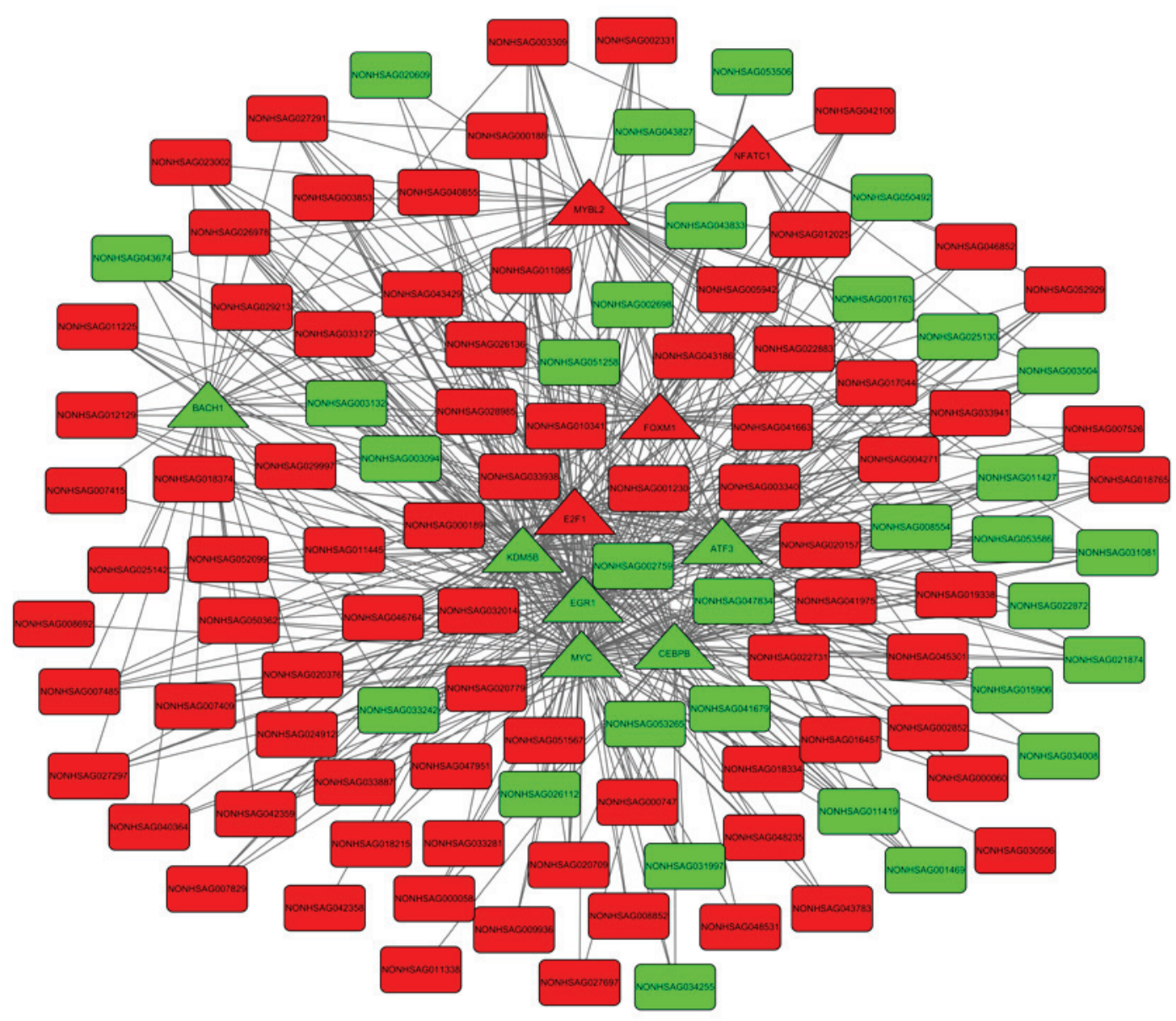

Figure 4. TF-lncRNA regulatory network. The red and green nodes represent upregulation and downregulation, respectively. The circles and rectangles indicate TFs and lncRNAs, respectively. TF, transcription factor; lncRNA, long non-coding RNA.

of $C D K 1$ and cell division cycle 25C $(39,40)$. AURKB functions in chromosome bi-orientation, spindle assembly and cytokinesis, and may be degraded by $\mathrm{APC} / \mathrm{C}$ bound to cadherin 1 in $\mathrm{G}_{1}$ and in late mitosis (41). In animal cells, $\mathrm{CDK} 2 /$ cyclin $\mathrm{E}$ can trigger initiation of centrosome duplication by targeting substrate nucleophosmin/B23 (42-44). Thus, the expression levels of $C D C 20, C C N B 1, A U R K B$ and $C D K 2$ may be associated with cell proliferation. In the PPI network for upregulated DEGs, it was observed that numerous DEGs demonstrated a certain level of interaction with each other, for example, CDK1-PLK1, CDC20-CCNB1, AURKB-CDK2 and $C D K 1-A U R K B$. Therefore, it may be other genes, including $P L K 1$ and $C C N B$, which had interaction with $C D C 20, C C N B 1, A U R K B$ and $C D K 2$, may also function in cell proliferation.

The proto-oncogene $M Y C$ encodes transcription factor c-myc which is associated with regulation of cell proliferation and differentiation (45). Conditional activation or constitutive expression of wild-type $C E B P B$ may promote differentiation and suppress proliferation of 32D-BCR/ABL cells, which is contrary to a DNA binding-deficient $C E B P B$ mutant (46). It is reported that $E 2 F 1, E 2 F 2$ and $E 2 F 3$ function as transcriptional activators in the process of the $\mathrm{G}_{1} / \mathrm{S}$ transition (47). As a member of the Egr transcription factor family, EGRl is involved in cell growth, proliferation and stress responses in various types of tissues (48). This may suggest the expression levels of $C E B P B, E 2 F 1, E G R 1$ and $M Y C$ were associated with cell proliferation. In the TF-DEG regulatory network, it was observed that TFs could target $C D K 1, P L K 1, C C N B 1$ and $A U R K B$, for example $M Y C \rightarrow P L K 1, M Y C \rightarrow C C N B 1$, $M Y C \rightarrow A U R K B, C E B P B \rightarrow A U R K B, E 2 F 1 \rightarrow C D K 1$ and $E 2 F 1 \rightarrow C C N B 1$, suggesting that TFs may be involved in cell proliferation via regulation of $C D K 1, P L K 1, C C N B 1$ and AURKB.

In conclusion, the present study conducted a comprehensive bioinformatics analysis of genes that may be associated with cell proliferation. A total of 178 differentially expressed lncRNA were identified, and additionally, 365 upregulated and 142 downregulated genes were screened. It was indicated that $C D K 1, P L K 1, C D C 20, C C N B 1, A U R K B, C D K 2, C E B P B$, $E 2 F 1, E G R 1$ and $M Y C$ may be associated with cell proliferation of HHDPCs. Thus, PRP may be important in HHDPCs. Further investigation is required in order to elucidate the functional mechanisms of these genes in HHDPCs. In addition, the proliferative ability of HHDPCs treated with PRP will be investigated in future work.

\section{Acknowledgements}

The present study was supported by the Science and Technology Projects Fund of Hangzhou City (grant no. 20130633B04). 


\section{References}

1. Jahoda C, Horne K and Oliver R: Induction of hair growth by implantation of cultured dermal papilla cells. Nature 311: 1984 $560-562,1984$

2. Eppley BL, Woodell JE and Higgins J: Platelet quantification and growth factor analysis from platelet-rich plasma: Implications for wound healing. Plast Reconstr Surg 114: 1502-1508, 2004.

3. Kocaoemer A, Kern S, Klueter H and Bieback K: Human $\mathrm{AB}$ serum and thrombin-activated platelet-rich plasma are suitable alternatives to fetal calf serum for the expansion of mesenchymal stem cells from adipose tissue. Stem Cells 25 : 1270-1278, 2007.

4. Vogel JP, Szalay K, Geiger F, Kramer M, Richter W and Kasten P Platelet-rich plasma improves expansion of human mesenchymal stem cells and retains differentiation capacity and in vivo bone formation in calcium phosphate ceramics. Platelets 17: 462-469, 2006.

5. Mishra A, Tummala P, King A, Lee B, Kraus M, Tse V and Jacobs CR: Buffered platelet-rich plasma enhances mesenchymal stem cell proliferation and chondrogenic differentiation. Tissue Engineering Part C Methods 15: 431-435, 2009.

6. Reese RJ: Autologous platelet rich plasma (PRP): What do we know? Important concepts relevant to hair restoration surgery. Hair Transplant Forum Int 2010: 14-17, 2010.

7. Ito M, Yang Z, Andl T, Cui C, Kim N, Millar SE and Cotsarelis G: Wnt-dependent de novo hair follicle regeneration in adult mouse skin after wounding. Nature 447: 316-320, 2007.

8. Gilhar A and Kalish RS: Alopecia areata: A tissue specific autoimmune disease of the hair follicle. Autoimmun Rev 5: 64-69, 2006

9. Barsh G: Of ancient tales and hairless tails. Nat Genet 22 315-316, 1999.

10. Oro AE and Scott MP: Splitting hairs: Dissecting roles of signaling systems in epidermal development. Cell 95: 575-578, 1998.

11. Kulick D, Hark L and Deen D: The bariatric surgery patient: A growing role for registered dietitians. J Am Diet Assoc 110: 593-599, 2010 .

12. Oshima $\mathrm{H}$, Inoue $\mathrm{H}$, Matsuzaki $\mathrm{K}$, Tanabe $\mathrm{M}$ and Kumagai $\mathrm{N}$ : Permanent restoration of human skin treated with cultured epithelium grafting-wound healing by stem cell based tissue engineering. Hum Cell 15: 118-128, 2002.

13. Ito $\mathrm{M}$ and Kizawa K: Expression of calcium-binding S100 proteins A4 and A6 in regions of the epithelial sac associated with the onset of hair follicle regeneration. J Investig Dermatol 116 : 956-963, 2001

14. Kizawa K, Toyoda M, Ito M and Morohashi M: Aberrantly differentiated cells in benign pilomatrixoma reflect the normal hair follicle: Immunohistochemical analysis of Ca-binding S100A2, S100A3 and S100A6 proteins. Br J Dermatol 152: 314-320, 2005

15. Li YH, Zhang K, Yang K, Ye JX, Xing YZ, Guo HY, Deng F, Lian XH and Yang T: Adenovirus-mediated Wnt10b overexpression induces hair follicle regeneration. J Investig Dermatol 133: 42-48, 2013

16. Li YH, Zhang K, Ye JX, Lian XH and Yang T: Wnt10b promotes growth of hair follicles via a canonical Wnt signalling pathway. Clin Exp Dermatol 36: 534-540, 2011.

17. Nelson AM, Loy DE, Lawson JA, Katseff AS, FitzGerald GA and Garza LA: Prostaglandin D2 inhibits wound-induced hair follicle neogenesis through the receptor, Gpr44. J Investig Dermatol 133: 881-889, 2013.

18. Xiong Y, Li W, Shang C, Chen RM, Han P, Yang J, Stankunas K Wu B, Pan M, Zhou B, et al: Brg1 governs a positive feedback circuit in the hair follicle for tissue regeneration and repair. Dev Cell 25: 169-181, 2013.

19. Patel RK and Jain M: NGS QC Toolkit: A toolkit for quality control of next generation sequencing data. PLoS One 7: e30619, 2012.

20. Kim D, Pertea G, Trapnell C, Pimentel H, Kelley R and Salzberg SL: TopHat2: Accurate alignment of transcriptomes in the presence of insertions, deletions and gene fusions. Genome Biol 14: R36, 2013.

21. Karolchik D, Baertsch R, Diekhans M, Furey TS, Hinrichs A, Lu YT, Roskin KM, Schwartz M, Sugnet CW, Thomas DJ, et al: The UCSC genome browser database. Nucleic Acids Res 31: $51-54,2003$.
22. Trapnell C, Roberts A, Goff L, Pertea G, Kim D, Kelley DR, Pimentel H, Salzberg SL, Rinn JL and Pachter L: Differential gene and transcript expression analysis of RNA-seq experiments with TopHat and Cufflinks. Nat Protoc 7: 562-578, 2012

23. Tweedie S, Ashburner M, Falls K, Leyland P, McQuilton P, Marygold S, Millburn G, Osumi-Sutherland D, Schroeder A, Seal R, et al: FlyBase: Enhancing Drosophila gene ontology annotations. Nucleic Acids Res 37: D555-D559, 2009.

24. Kanehisa M and Goto S: KEGG: Kyoto encyclopedia of genes and genomes. Nucleic Acids Res 28: 27-30, 2000.

25. Wang J, Zhou X, Zhu J, Gu Y, Zhao W, Zou J and Guo Z: GO-function: Deriving biologically relevant functions from statistically significant functions. Brief Bioinform 13: 216-227, 2012.

26. Carlson M, Falcon S, Pages $\mathrm{H}$ and Li N: A set of annotation maps describing the entire Gene Ontology. Version 2.4.5, 2007.

27. Carlson M, Falcon S, Pages H and Li N: org. Hs. eg. db: Genome wide annotation for Human. Version 3.4.0, 2013

28. Franceschini A, Szklarczyk D, Frankild S, Kuhn M, Simonovic M, Roth A, Lin J, Minguez P, Bork P, von Mering C and Jensen LJ: STRING v9. 1: protein-protein interaction networks, with increased coverage and integration. Nucleic Acids Res 41: D808-D815, 2013.

29. Saito R, Smoot ME, Ono K, Ruscheinski J, Wang PL, Lotia S, Pico AR, Bader GD and Ideker T: A travel guide to Cytoscape plugins. Nat Methods 9: 1069-1076, 2012.

30. Thomas DJ, Rosenbloom KR, Clawson H, Hinrichs AS, Trumbower H, Raney BJ, Karolchik D, Barber GP, Harte RA, Hillman-Jackson J, et al: The ENCODE project at UC santa cruz. Nucleic Acids Res 35: D663-D667, 2007.

31. Ira G, Pellicioli A, Balijja A, Wang X, Fiorani S, Carotenuto W, Liberi G, Bressan D, Wan L, Hollingsworth NM, et al: DNA end resection, homologous recombination and DNA damage checkpoint activation require CDK1. Nature 431: 1011-1017, 2004.

32. Santamaría D, Barrière $C$, Cerqueira $A$, Hunt $S$, Tardy $C$, Newton K, Cáceres JF, Dubus P, Malumbres M and Barbacid M: Cdk1 is sufficient to drive the mammalian cell cycle. Nature 448: 811-815, 2007.

33. Petronczki M, Lénárt P and Peters JM: Polo on the rise-from mitotic entry to cytokinesis with Plk1. Dev Cell 14: 646-659, 2008.

34. Sumara I, Giménez-Abián JF, Gerlich D, Hirota T, Kraft C, de la Torre C, Ellenberg J and Peters JM: Roles of polo-like kinase 1 in the assembly of functional mitotic spindles. Curr Biol 14: 1712-1722, 2004.

35. Spänkuch-Schmitt B, Bereiter-Hahn J, Kaufmann M and Strebhardt K: Effect of RNA silencing of polo-like kinase-1 (PLK1) on apoptosis and spindle formation in human cancer cells. J Natl Cancer Inst 94: 1863-1877, 2002.

36. Gumireddy K, Reddy MR, Cosenza SC, Boominathan R, Baker SJ, Papathi N, Jiang J, Holland J and Reddy EP: ON01910, a non-ATP-competitive small molecule inhibitor of Plk1, is a potent anticancer agent. Cancer Cell 7: 275-286, 2005.

37. Yu H: Cdc20: A WD40 activator for a cell cycle degradation machine. Mol Cell 27: 3-16, 2007.

38. Kramer ER, Scheuringer N, Podtelejnikov AV, Mann M and Peters JM: Mitotic regulation of the APC activator proteins CDC20 and CDH1. Mol Biol Cell 11: 1555-1569, 2000.

39. Fang Y, Yu H, Liang X, Xu J and Cai X: Chk1-induced CCNB1 overexpression promotes cell proliferation and tumor growth in human colorectal cancer. Cancer Biol Ther 15: 1268-1279, 2014.

40. Abel D, Abdul-Hamid O, Dijk M and Oudejans CB: Transcription factor STOX1A promotes mitotic entry by binding to the CCNB1 promotor. PLoS One 7: e29769, 2012.

41. Stewart S and Fang G: Destruction box-dependent degradation of aurora B is mediated by the anaphase-promoting complex/cyclosome and Cdh1. Cancer Res 65: 8730-8735, 2005.

42. Okuda M, Horn HF, Tarapore P, Tokuyama Y, Smulian AG, Chan PK, Knudsen ES, Hofmann IA, Snyder JD, Bove KE and Fukasawa K: Nucleophosmin/B23 is a target of CDK2/cyclin E in centrosome duplication. Cell 103: 127-140, 2000.

43. Tarapore P, Okuda M and Fukasawa K: A mammalian in vitro centriole duplication system: Evidence for involvement of $\mathrm{CDK} 2 /$ cyclin E and nucleophosmin/B23 in centrosome duplication. Cell Cycle 1: 75-78, 2002.

44. Tokuyama Y, Horn HF, Kawamura K, Tarapore $\mathrm{P}$ and Fukasawa K: Specific phosphorylation of nucleophosmin on $\operatorname{Thr}(199)$ by cyclin-dependent kinase 2-cyclin E and its role in centrosome duplication. J Biol Chem 276: 21529-21537, 2001. 
45. Wu KJ, Grandori C, Amacker M, Simon-Vermot N, Polack A, Lingner J and Dalla-Favera R: Direct activation of TERT transcription by c-MYC. Nat Genet 21: 220-224, 1999.

46. Guerzoni C, Bardini M, Mariani SA, Ferrari-Amorotti G, Neviani P, Panno ML, Zhang Y, Martinez R, Perrotti D and Calabretta B: Inducible activation of $\mathrm{CEBPB}$, a gene negatively regulated by $\mathrm{BCR} / \mathrm{ABL}$, inhibits proliferation and promotes differentiation of BCR/ABL-expressing cells. Blood 107: 4080-4089, 2006
47. Wu L, Timmers C, Maiti B, Saavedra HI, Sang L, Chong GT, Nuckolls F, Giangrande P, Wright FA, Field SJ, et al: The E2F1-3 transcription factors are essential for cellular proliferation. Nature 414: 457-462, 2001.

48. Min IM, Pietramaggiori G, Kim FS, Passegué E, Stevenson KE and Wagers AJ: The transcription factor EGR1 controls both the proliferation and localization of hematopoietic stem cells. Cell stem cell 2: 380-391, 2008. 